\title{
Investigation of lactobacillus gasseri ma-2 as probiotic candidate
}

\author{
Meltem ASAN ÖZÜSA ĞLAM ${ }^{1 *(D)}$, Ayşe GÜNYAKTI ${ }^{1,2 *(D)}$ \\ ${ }^{1}$ Department of Biotechnology and Molecular Biology, Faculty of Science and Letters, Aksaray University, 68100 \\ Aksaray, Turkey \\ ${ }^{2}$ Institute of Biotechnology, Ankara University, Ankara, Turkey
}

\begin{abstract}
Characterization of lactic acid bacteria in human milk has become an interesting field for developing new probiotics. Therefore, some probiotic properties of Lactobacillus gasseri MA2 strain isolated before from human breast milk were screened in vitro. MA-2 strain exhibited safety aspects with no hemolytic activity ( $\gamma$-hemolytic activity) and sensitivity to penicillin $G$, cloxacillin and chloramphenicol. The remarkable tolerance to various acid, bile, pepsin and pancreatin conditions was determined with high survival rate. The strain also presented significant auto-aggregation $(93 \%)$ as well as co-aggregation activity with pathogenic microorganisms. L. gasseri MA-2 originated from human milk exhibited promising probiotic properties.
\end{abstract}

\section{Article info \\ History:}

Received:03.12.2019

Accepted:03.02.2020

Keywords:

Probiotic,

Human milk,

Survival,

Gastrointestinal

condition,

Aggregation.

\section{Introduction}

Human breast milk is known as the primary source for healthy and rapidly growth of newborns. It includes high amounts of necessary nutrients, prebiotic substances and mutualistic, commensal and potentially probiotic bacteria for infants [1,2]. The microorganism content in human milk is affected by microorganisms in the mother's gut transported by dendritic cells and macrophages from the lymphatic system through the mammary glands and on the surface of the breast [3, 4]. Human milk generally contains $10^{3}-10^{5} \mathrm{CFU} / \mathrm{ml}$ viable bacteria [5]. Commonly isolated bacteria genera from human milk are including Bifidobacterium, Staphylococcus, Enterococcus, Streptococcus as well as Lactobacillus [3]. Some strains in milk belonging to lactic acid bacteria (LAB) like Lactobacillus gasseri, L. fermentum, L. salivarius, Bifidobacterium longum subsp. infantis, $B$. breve have been indicated as promoting normal gut bacterial colonization and preventing diarrhea [6-8]. LAB originated from human breast milk have been interesting because of their probiotic potential, ability to remain in the intestine as well as being human origin [9]. Human milk is a natural source of a potential probiotic or biotherapeutic LAB. L. gasseri strains in human milk are considered as the potential probiotic bacteria and used in various commercial probiotic products [9].
Probiotics are living microorganisms when used in sufficient amounts and provide health benefits to the host [10]. Being safe is the most important criteria to evaluate a microorganism as a probiotic culture [11]. The other selection criteria are survival in stomach acidity and bile salts [12]. They should also be resistant to pepsin and pancreatic juice [13]. Adherence to mucus and/or human epithelial cells and activity to reduce pathogen adhesion to surface are the main used in vitro assays for probiotic candidate microorganism [14]. The aim of this study was to evaluate the probiotic potential of $L$. gasseri MA-2 strain previously isolated from human breast milk and characterized some biotechnological aspects [15].

\section{Materials and Methods}

\subsection{Safety evaluation}

The hemolytic property was tested on Colombia agar plate containing $5 \%(\mathrm{w} / \mathrm{v})$ sheep blood (OR-BAK). The inoculated plate was incubated for $24 \mathrm{~h}$ at $37^{\circ} \mathrm{C}$ and then examined for the hemolytic activity. The formation of clean and greenish zones on the plates was evaluated as $\beta$-hemolysis and $\alpha$-hemolysis. No zones around the colonies were determined as $\gamma$ hemolytic (non-hemolytic activity).

The antibiotic susceptibility was determined using disc diffusion method. The culture adjusted to Mc Farland 
0.5 was streaked on MRS-Agar plates. Antibiotic discs (Oxoid) were put on the inoculated plates and then incubated at $37^{\circ} \mathrm{C}$ for $24 \mathrm{~h}$. The antibiotic susceptibility aspect of the strain was tested using amikacin (AK, 10 $\mu \mathrm{g} / \mathrm{disc}$ ), chloramphenicol (C, $10 \mu \mathrm{g} /$ disc), cloxacillin (OB, $5 \mu \mathrm{g} / \mathrm{disc}$ ), nalidixic acid (NA, $5 \mu \mathrm{g} / \mathrm{disc}$ ), ofloxacin (OFX, $5 \mu \mathrm{g} / \mathrm{disc}$ ), penicillin $\mathrm{G}$ (P, 10 $\mu \mathrm{g} / \mathrm{disc})$. The diameter of the inhibition zone was measured using Vernier caliper. The results were examined according to Clinical and Laboratory Standards Institute (CLSI, 2012) standards as susceptible $(\mathrm{S})>20 \mathrm{~mm}$, intermediate $(\mathrm{IR}) \cong 15-19$ $\mathrm{mm}$, resistant $(\mathrm{R}) \leq 14 \mathrm{~mm}[16]$.

\subsection{Determination survival in gastrointestinal conditions}

\subsubsection{Tolerance to low $\mathbf{p H}$ conditions}

The tolerance of MA-2 strain to low $\mathrm{pH}$ environments was screened in vitro at different values in MRS broth. The overnight culture (16-18 $\mathrm{h}$ incubation) of the strain (1\%) was inoculated in MRS broth (pH 2 and 3) and incubated at $37^{\circ} \mathrm{C} .0 .1 \mathrm{ml}$ inoculum was taken from each tube at the end of 0,1 and $3 \mathrm{~h}$ incubation time. The inoculums were then diluted and plated on MRS agar. The plates were incubated under anaerobic conditions at $37^{\circ} \mathrm{C}$ for $24 \mathrm{~h}$ for the determination of cell viability. The viable cells were counted and presented as $\log _{10}$ values of colony forming units per milliliter (CFU/ml) [17].

\subsubsection{Tolerance to bile salt conditions}

The bile tolerance of the strain was determined in MRS broth containing $0.3 \%$ and $1 \%$ of bile (Oxoid). The overnight culture $(1 \%)$ was inoculated in MRS broth containing bile and then incubated for $4 \mathrm{~h}$ at $37^{\circ} \mathrm{C}$. The cultures were withdrawn at 0 and $4 \mathrm{~h}$ interval and diluted. The cell suspension was plated on MRS agar. The plates were incubated under anaerobic conditions for $24 \mathrm{~h}$ at $37^{\circ} \mathrm{C}$. The tolerance to bile was determined by enumerating the viable cells on the agar plate and calculated in Log10 (CFU/ml) [18].

\subsubsection{Tolerance to simulated gastric and pancreatic juice}

The tolerance of MA-2 strain to simulate gastric transit was performed using the simulated gastric solution containing $3 \mathrm{mg} / \mathrm{ml}$ pepsin (Sigma-Aldrich) adjusted to $\mathrm{pH} 2$ and 3. The gastric solution was inoculated (1\%) with the bacterial suspension (McFarland 0.5 standard) and incubated at $37^{\circ} \mathrm{C}$ for $3 \mathrm{~h}$. The viable cell count was determined on MRS agar plates by the spread of before and after incubation of the suspension samples after $24 \mathrm{~h}$ incubation under anaerobic condition. The viable cell was counted and the percentage survival of the bacteria was calculated in $\log _{10}(\mathrm{CFU} / \mathrm{ml})$ [19]. The survival rate was calculated using the following equation:

Survival rate $(\%)=\frac{\text { After incubation } \log \mathrm{CFU} / \mathrm{ml}}{\text { Before incubation Log CFU } / \mathrm{ml}} \times 100$

For pancreatic tolerance, the simulated intestine fluid prepared by dissolving pancreatin $(1 \mathrm{mg} / \mathrm{ml}$, SigmaAldrich) and bile salt $(0.03 \mathrm{mg} / \mathrm{ml}$, Oxoid $)$ was inoculated with MA-2 culture (McFarland 0.5 standard turbidity, $1 \%$ ) and incubated at $37^{\circ} \mathrm{C}$ for $3 \mathrm{~h} \mathrm{[19].} \mathrm{The}$ viable cell count and survival rate were determined in the same manner as for the determination of the gastric juice tolerance.

\subsection{Abilities of auto-aggregation and co- aggregation}

The ability of MA-2 strain to auto aggregate and coaggregate were obtained according to $\mathrm{Xu}$ et al. [20].The overnight culture of the strain was harvested by centrifugation and washed with PBS twice. Then, the cell suspension prepared in PBS buffer was adjusted to $0.6 \pm 0.02$ at $\mathrm{OD}_{600} \mathrm{~nm}$. The sample was incubated without any movement at $37^{\circ} \mathrm{C}$ for $4 \mathrm{~h}$. After the incubation, the sample $(0.1 \mathrm{ml})$ was then suspended in PBS buffer $(3.9 \mathrm{ml})$. The suspension was read at 600 $\mathrm{nm}$ using a spectrophotometer (Beckman Coulter). The auto-aggregation was calculated using the formula:

Auto - aggregation $\%=\frac{\mathrm{OD} 1-\mathrm{OD} 2}{\mathrm{OD} 1} \times 100$

where OD1 represents pre-incubation absorbance and OD2 represents after incubation absorbance

The co-aggregation ability of the strain was assayed using various pathogen microorganisms such as $L$. monocytogenes ATCC 7644, E. coli ATCC 35218, E. coli O157:H7, S. enteritidis ATCC 13076, $S$. enteritidis RSKK 171, S. agalactiae and $V$. alginolyticus. The equal volumes $(2 \mathrm{ml})$ of $L$. gasseri MA-2 prepared as described above for autoaggregation test and each pathogenic bacterium were mixed and incubated at $37^{\circ} \mathrm{C}$ for $4 \mathrm{~h}$. After incubation period, $0.1 \mathrm{ml}$ of mixed suspension, resuspended in 3.9 $\mathrm{ml}$ of PBS buffer and read at $\mathrm{OD}_{600} \mathrm{~nm}$ in the spectrophotometer. The co-aggregation ability was calculated with the following formula:

Co - aggregation $\%=\frac{(\mathrm{OD} 1+\mathrm{OD} 2)-2(\mathrm{OD} 3)}{(\mathrm{OD} 1+\mathrm{OD} 2)} \times 100$

where OD1 presents pre-incubation absorbance, OD2 presents pre-incubation absorbance of pathogen strain 
and OD3 presents absorbance of mixed strains (after 4 h).

\section{Results and Discussion}

\subsection{Safety aspects of $L$. gasseri MA-2 strain}

The strain showed no clear or greenish zones on the blood agar around their colonies (Figure 1). MA-2 strain was therefore evaluated as $\gamma$-hemolytic or nonhemolytic. Absence of hemolytic activity is evaluated as safe precondition for the selection of probiotic strain [12].

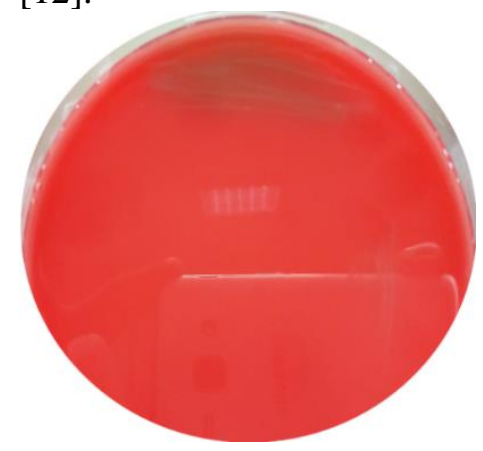

The antibiotic susceptibility assay results indicated that the strain was sensitive to chloramphenicol and cloxacillin, in addition to penicillin $\mathrm{G}$ (Table 1). In the reports, Lactobacillus is generally susceptible to ampicillin and penicillin (beta-lactam antibiotics) and broad-spectrum antibiotics [21]. L. gasseri MA-2 had resistance to amikacin, nalidixic acid and ofloxacin. Probiotic bacteria are capable of harboring intrinsic and mobile genetic elements that provide resistance to various antibiotics. Probiotics added to diets can form an antibiotic-resistant gene reservoir in the human intestine and transfer to pathogens found in the same habitat [22]. In the literature, the antibiotic resistance of Lactobacillus strains is recognized to be intrinsic or natural encoded on the chromosome and recognized as non-transferable. The resistance of Lactobacillus genus to aminoglycoside antibiotics, such as Amikacin, Streptomycin, Kanamycin and Gentamicin is regarded as intrinsic because of their lack of cytochrome-mediated electron transport mediating drug uptake [23].

Fig. 1. $\gamma$-hemolytic activity of L. gasseri MA-2.

Table 1. Antibiotic susceptibility of L. gasseri MA-2

\begin{tabular}{lllllll}
\hline \multirow{2}{*}{ L. gasseri MA-2 } & \multicolumn{7}{l}{ Inhibition zone diameter $(\mathbf{m m})$} \\
\cline { 2 - 7 } & AK & C & OB & NA & OFX & P \\
\hline Mean \pm standard & $-^{\mathrm{a}}$ & $20.72 \pm$ & $23.68 \pm$ & - & - & $33.19 \pm$ \\
deviation & & $0.91^{\mathrm{b}}$ & 2.40 & & & 1.26 \\
\hline CLSI $^{\mathrm{c}}$ & $\mathrm{R}$ & $\mathrm{S}$ & $\mathrm{S}$ & $\mathrm{R}$ & $\mathrm{R}$ & $\mathrm{S}$ \\
\hline
\end{tabular}

${ }^{\mathbf{a}}$ : no inhibition zone. ${ }^{\mathbf{b}}$ : the inhibition zone diameter including disc diameter ${ }^{\mathbf{c}}$ : Clinical and Laboratory Standards Institute

AK: Amikacin, C: Chloramphenicol, OB: Cloxacillin, NA: Nalidixic Acid, OFX: Ofloxacin, P: Penicillin G, R: Resistant, S: Sensitive

\subsection{Tolerance to Gastrointestinal Conditions}

The viability in the gastrointestinal system should be approved by in-vitro studies prior to use a bacterium as probiotic candidate [24]. Therefore, the strain should be able to resist low $\mathrm{pH}$ values of gastric juice and resistant to bile salts. The $\mathrm{pH}$ of the gastric juice is considered to be one of the main criterions affecting the viability of probiotic bacteria in the transition from the stomach to the intestine [25]. In the study, the tolerance of MA-2 strain to different $\mathrm{pH}$ conditions (pH 2 and 3) was determined. From the data, the strain showed remarkable survival with $4.64 \mathrm{CFU} / \mathrm{ml}$ and $5.52 \mathrm{CFU} / \mathrm{ml}$ when exposure to $\mathrm{pH} 2$ and $\mathrm{pH} 3$ after the incubation period ( $3 \mathrm{~h}$ ) (Figure 2). The strain has never lost its survival at both tested $\mathrm{pH}$ conditions. The survival rate of MA-2 strain was determined as $74 \%$ and $87.75 \%$ after exposure to $\mathrm{pH} 2$ and $\mathrm{pH} 3$. Singroha et al. [26] reported the survival of nine L. gasseri strains obtained from ATCC at $\mathrm{pH} 2$ after $3 \mathrm{~h}$ as varying from $8.7 \mathrm{CFU} / \mathrm{ml}$ to $9.1 \mathrm{CFU} / \mathrm{ml}$. However, Oh et al. [27] indicated that L. gasseri 4M13 strain from infant feces showed $6.44 \mathrm{CFU} / \mathrm{ml}$ of viability at $\mathrm{pH} 3$ after $2 \mathrm{~h}$. 


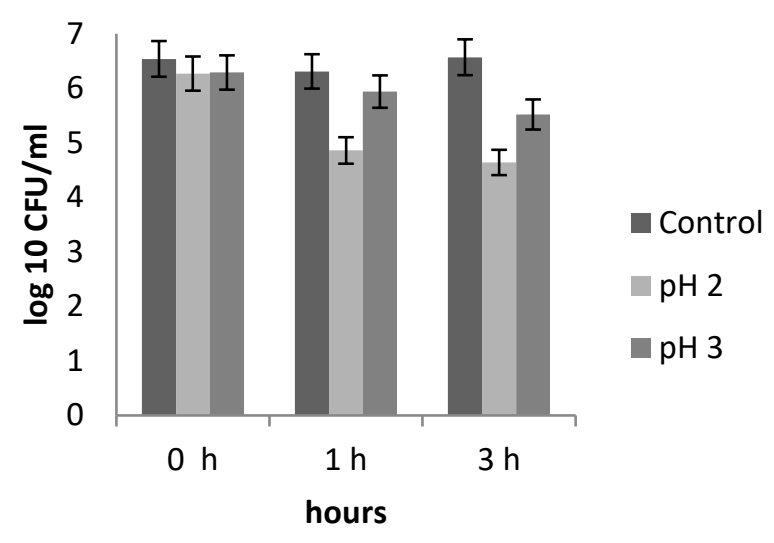

Figure 2. Acid tolerance of L. gasseri MA-2.

Bile plays an essential role in the intestinal tract related with non-specific and specific defense mechanisms, and the significance of the inhibitory effect is fundamentally determined by the concentration of bile salts. The bile tolerance is therefore considered an important feature of probiotic candidate LAB strains which allows them to survive and continue their activities in the gastrointestinal system [28]. MA-2 strain was exposed to different bile conditions $(0.3 \%$ and $0.1 \%$ ) at the incubation period of $4 \mathrm{~h}$. The strain showed good viability with $7.02 \mathrm{CFU} / \mathrm{ml}$ and 5.36 $\mathrm{CFU} / \mathrm{ml}$ at $0.3 \%$ and $0.1 \%$ bile concentrations after $4 \mathrm{~h}$ incubation (Figure 3 ). The viability of $L$. gasseri $4 \mathrm{M} 13$ from infant feces was reported as $6.45 \mathrm{CFU} / \mathrm{ml}$ after 6 $\mathrm{h}$ at $1 \%$ bile condition [27].

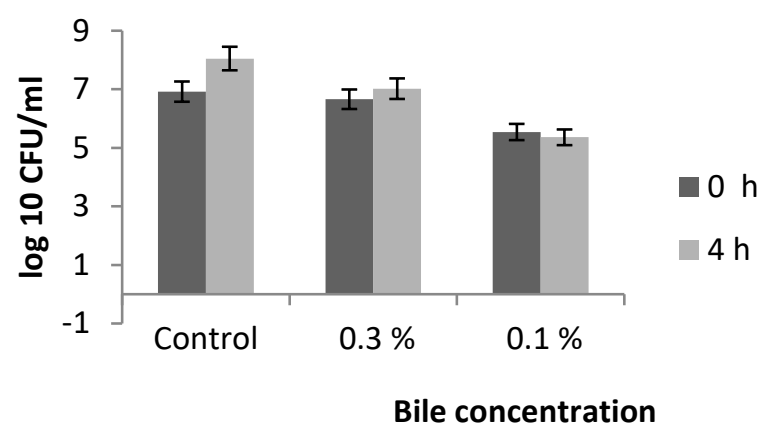

Figure 3. Bile tolerance of L. gasseri MA-2.

MA-2 strain was also assayed for colonization in the gastrointestinal system by investigating its viability in the simulated gastric and pancreatic conditions. The strain exhibited survival in both gastric and pancreatic conditions which indicates colonizing the intestines. The viable cell count of the strain showed that there was a bit decrease in the survival at $\mathrm{pH} 2$ gastric juice conditions with $93.33 \%$ survival rate (Table 2). However, at $\mathrm{pH} 3$ condition, the strain exhibited higher survival rate $(103.62 \%)$ than $\mathrm{pH} 2$ gastric environments. MA-2 strain also showed remarkable survival rate $(95.43 \%)$ at pancreatic juice condition after $3 \mathrm{~h}$. The data indicated that $L$. gasseri MA-2 strain exhibited good survival ability under gastrointestinal conditions. Therefore, MA-2 strain could be potential candidate to evaluate a probiotic strain.

Table 2. Simulated gastric and pancreatic juice tolerance of L. gasseri MA-2

\begin{tabular}{|c|c|c|c|c|c|c|c|c|}
\hline \multicolumn{6}{|c|}{ Gastric Juice } & \multirow{2}{*}{\multicolumn{2}{|c|}{$\begin{array}{c}\text { Pancreatic } \\
\text { juice } \\
\left(\log _{10}\right. \\
\text { CFU/ml) }\end{array}$}} & \multirow{3}{*}{$\begin{array}{c}\text { Survival } \\
\text { rate } \\
(\%)\end{array}$} \\
\hline $\begin{array}{r}\mathrm{pH} \\
(1 \\
\mathrm{CF}\end{array}$ & $\begin{array}{l}2.0 \\
g_{10} \\
/ \mathrm{ml})\end{array}$ & $\begin{array}{l}\text { Survival } \\
\text { rate }(\%)\end{array}$ & $\begin{array}{r}\mathrm{pH} \\
\text { (lo } \\
\mathrm{CFL}\end{array}$ & $\begin{array}{l}3.0 \\
y_{10} \\
\text { /ml) }\end{array}$ & $\begin{array}{l}\text { Survival } \\
\text { rate }(\%)\end{array}$ & & & \\
\hline $0 . \mathrm{h}$ & 3.h & & $0 . \mathrm{h}$ & 3.h & & $0 . \mathrm{h}$ & 3.h & \\
\hline 8.69 & 8.11 & 93.33 & 7.72 & 8.00 & 103.62 & 8.97 & 8.56 & 95.43 \\
\hline
\end{tabular}

\subsection{Auto-aggregation and co-aggregation abilities of L. gasseri MA-2 strain}

Auto-aggregation and co-aggregation activities of a probiotic strain are important probiotic properties. MA-2 strain exhibited a strong auto-aggregating ability (93\%) (Figure 4). The co-aggregation of the strain with five human (E. coli ATCC 35218, $L$. monocytogenes ATCC 7644, E. coli O157:H7, S. enteritidis RSKK 171 and S. enteritidis ATCC 13076) and two fish originated bacteria (V. alginolyticus and S. agalactiae) was also examined. The co-aggregation ability of the strain varied from $36 \%$ to $51 \%$ (Figure 4 ). L. gasseri MA-2 demonstrated marked co-aggregation (51\%) with S. enteritidis ATCC 13076 among the tested bacteria. Auto-aggregation of probiotic strains is related with adhesion to intestinal epithelial cells to survive in the gastrointestinal system [29]. The coaggregation ability of probiotic strains may allow the formation of a defensive barrier by preventing colonization of pathogenic bacteria [30]. Autoaggregation properties together with co-aggregation abilities with pathogens are the important criterions in the formation of biofilm protects the host from pathogen colonization [31]. L. gasseri MA-2 with high aggregation capabilities can be a good barrier to pathogen microorganisms. 


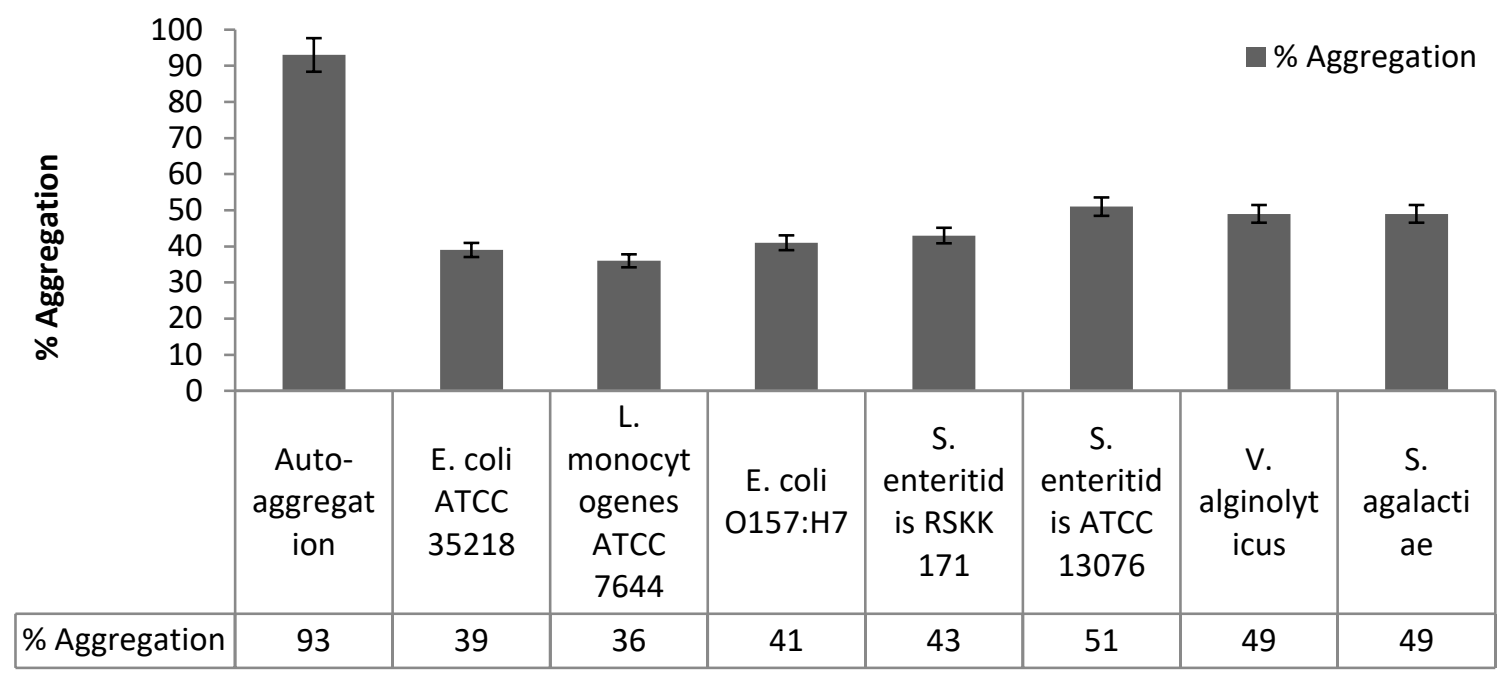

Figure 4. Auto-aggregation and co-aggregation activities of L. gasseri MA-2.

\section{Conclusions}

L. gasseri MA-2 originated from human milk was investigated for its potential probiotic aspects. MA-2 strain could survive in the simulated gastric environment such as acid, bile, pepsin and pancretain. The strain showed a good ability to grow and survive well in the gastrointestinal conditions with high survival rate. The strain could form defense system for host with high auto-aggregation and co-aggregation abilities. The results showed that L. gasseri MA-2 strain with safety features is a suitable candidate for food and pharmaceutical industries as bioactive supplement to promote health and continue the natural balance in the gastrointestinal system of host.

\section{Conflicts of interest}

The authors state that did not have conflict of interests.

\section{References}

[1] Dai D. and Walker W. A., Protective nutrients and bacterial colonization in the immature human gut, Advances in Pediatrics, 46 (1999) 353-382.

[2] Martín R., Langa S., Reviriego C., Jiménez E., Marín M.L., Xaus J., Fernández L. and Rodríguez J.M., Human milk is a source of lactic acid bacteria for the infant gut, Journal of Pediatrics, 143 (2003) 754-758.

[3] Jeurink P.V., van Bergenhenegouwen J., Jimenez E., Knippels L.M, Fernandez L.,
Garssen J., Knol J., Rodriguez J.M. and Martin R., Human milk: a source of more life than we imagine, Benef. Microbes, 4 (2013) 17-30.

[4] Fitzstevens J.L., Smith K.C., Hagadorn J.I.,Caimano M.J., Matson A.P. and Brownell E.A., Systematic review of the human milk microbiota, Nutr. Clin. Pract., 32 (2017) 354364.

[5] Perez P.F., Dore J., Leclerc M., Levenez F., Benyacoub J., Serrant P., Segura-Roggero I, Schiffrin E.J. and Donnet-Hughes A., Bacterial imprinting of the neonatal immune system: lessons from maternal cells?, Pediatrics, 119 (2007) e724-e732.

[6] Chiu Y.-H., Tsai J.-J., Lin S.-L., Choritosvakin C. and Lin M.-Y., Characterisation of bifidobacteria with immunomodulatory properties isolated from human breast milk, $J$. Funct. Foods, 7 (2014) 700-708.

[7] Moles L., Escribano E., Andrés, J. De Montes M.T., Rodríguez J.M., Jiménez E., Sáenz de Pipaón M. and Espinosa-Martos I., Administration of Bifidobacterium breve PS12929 and Lactobacillus salivarius PS12934, two strains isolated from human milk, to very low and extremely low birth weight preterm infants: a pilot study, J. Immunol. Res., (2015) 538171. doi: 10.1155/2015/538171

[8] Shin S.P., Choi Y.M., Kim WH., Hong S.P., Park J.M., Kim J., Kwon O., Lee E.H. and Hahm K.B., A double blind, placebo-controlled, randomized clinical trial that breast milk derived-Lactobacillus gasseri BNR17 mitigated 
diarrhea-dominant irritable bowel syndrome, $J$. Clin. Biochem. Nutr., 62 (2018) 179-186.

[9] Martín R., Langa S., Reviriego C., Jiménez E., Marín M.L., Olivares M., Boza J., Jiménez J., Fernandez L. and Xaus J., The comensal microflora of human milk: new perspectives for food bacteriotherapy and probiotics, Trends Food Sci. Technol., 15 (2004) 121-127.

[10] Morelli L. and Capurso L., FAO/WHO guidelines on probiotics 10 years latter, J. Clin. Gastroenterol., 46 (2012) 1-2.

[11] Barbosa F.H.F., Barbosa L.P.J.L., Bambirra L.H.S. and Aburjaile F.F., Probioticos microrganismos a favor da vida, Rev. Biol. Cien. Terra, 11 (2011) 11-21.

[12] FAO/WHO, Guidelines for the Evaluation of Probiotics in Food, Food and Agriculture Organization (FAO), World Health Organization (WHO), Geneva, Switzerland, 2002.

[13] Gupta V. and Garg R., Probiotics, Indian J. Med. Microbiol., 27 (2009) 202-209.

[14] FAO/WHO, Working Group Report on Drafting Guidelines for the Evaluation of Probiotics in Food London, Ontario, Canada; April 30 and May 1, 2002.

[15] Gunyakti A. and Asan-Ozusaglam M., Lactobacillus gasserifrom human milk with probiotic potential and some technological properties, LWT - Food Science and Technology, 109 (2019) 261-269.

[16] Clinical and Laboratory Standards Institute. Performance Standards for Antimicrobial Susceptibility Testing: Twenty- Second Informational Supplement. CLSI Document M100-S22, Clinical Laboratory Standard Institute, Wayne, PA. ISBN 1-56238-785-5, (Print); ISBN 1-56238-786-3 (2012) (Electronic)

[17] Zoral S., İnsan kaynaklı Lactobacillus spp. Suşlarının probiyotik özelliklerinin belirlenmesi. MSc thesis, University of Ahi Evran, Kırşehir, Turkey, 2013.

[18] Tokatl1 M., Identification of lactic acid bacteria isolated from pickles in Ankara Çubuk region, determination of their technological and functional properties and their potential for using as a starter culture, $\mathrm{PhD}$ thesis, University of Ankara, Ankara, Turkey, 2013.

[19] Yürümez E., Probiotics properties of some lactic acid bacteria isolated from faeces samples. MSc thesis, University of Ankara, Ankara, Turkey, 2011.

[20] Xu H., Jeong H.S., Lee H.Y. and Ahn J., Assessment of cell surface properties and adhesion potential of selected probiotic strains. Lett. Appl. Microbiol., 49 (2009) 434-442.

[21] Georgieva R., Yocheva L., Tserovska L., Zhelezova G., Stefanova N., Atanasova A., Danguleva A., Ivanova G., Karapetkov N., Rumyan N. and Karaivanova E., Antimicrobial activity and antibiotic susceptibility of Lactobacillus and Bifidobacterium spp. intended for use as starter and probiotic cultures, Biotechnol. Biotechnol. Equip., 29 (2015) 8491.

[22] Zheng M., Zhang R., Tian X., Zhou X., Pan X. and Wong A., Assessing the risk of probiotic dietary supplements in the context of antibiotic resistance, Front. Microbiol., 8 (2017) 908. doi: 10.3389/fmicb.2017.00908

[23] Danielsen M. and Wind A., Susceptibility of Lactobacillus spp. to antimicrobial agents, Int.J. Food Microbiol., 82 (2003) 1-11.

[24] Berardi C. W., Solovey E.T. and Cummings M.L., Investigating the efficacy of network visualizations for intelligence tasks, in Proceedings of the IEEE International Conference on Intelligence and Security Informatics (Seattle, WA), (2013) 278-283.

[25] Plessas S., Nouska C., Karapetsas A., Kazakos S., Alexopoulos A., Mantzourani I., Chondrou P., Fournomiti M., Galanis A. and Bezirtzoglou E., Isolation, characterization and evaluation of the probiotic potential of a novel Lactobacillus strain isolated from Feta-type cheese, Food Chem., 226 (2017) 102-108.

[26] Singroha G., Mishra S.K. and Malik R.K., Isolation and characterization of potential probiotic Lactobacillus gasseri strains isolated from different sources, Int. J. Food. Ferment., 6 (2017) 71-83.

[27] Oh N.S., Joung J.Y., Lee J.Y. and Kim Y., Probiotic and anti-inflammatory potential of Lactobacillus rhamnosus 4B15 and Lactobacillus gasseri 4M13 isolated from infant feces. PLoSONE, 13(2) (2018) e0192021. https://doi.org/10.1371/journal.pone.0192021

[28] Argyri A.A.,Zoumpopoulou G., Karatzas K.A., Tsakalidou E., Nychas G.J., Panagou E.Z. and Tassou C.C., Selection of potential probiotic lactic acid bacteria from fermented olives by in vitro tests, Food Microbiol., 33 (2013) 282-291.

[29] Ferreira C.L., Grześkowiak L., Collado M.C. and Salminen S., In vitro evaluation of Lactobacillus gasseri strains of infant origin on adhesion and aggregation of specific pathogens, J. Food Prot., 74 (2011) 1482-1487.

[30] Twetman L., Larsen U., Fiehn N.-E., Steckse nBlicks C. and Twetman S., Coaggregation 
between probiotic bacteria and caries-associated strains: An in vitro study, Acta Odontol. Scand., 67 (2009) 284-288.
[31] Ocaña V.S. and Nader-Macias M.E., Vaginal lactobacilli: Self- and co-aggregating ability, $\mathrm{Br}$. J. Biomed. Sci., 59 (2002) 183-190. 